\title{
ESTUDOS DE ESPAÇAMENTOS PARA Tephrosia candida
}

\author{
Sérgio José Alves*, Wilian da Silva Ricce** \\ *Eng. Agrônomo, Dr., IAPAR - sja@iapar.br \\ **Eng. Agrônomo, Mestrando em Agronomia, UEL - wilianricce@conectway.com.br \\ Recebido para publicação: 17/01/2006 - Aceito para publicação: 13/09/2006
}

\begin{abstract}
Resumo
O objetivo deste trabalho foi avaliar a produção de sementes e de biomassa total (raízes, ramos e folhas) de Tephrosia candida DC em diferentes espaçamentos entre linhas e épocas de corte. $\mathrm{O}$ experimento foi realizado no campo, com delineamento em blocos ao acaso, com parcelas subdivididas. Nas parcelas, foram testados 5 espaçamentos entre linhas: 20, 40, 60, 80 e $120 \mathrm{~cm}$, e nas subparcelas, 3 épocas de corte: 12, 18 e 24 meses a partir da semeadura. O espaçamento na linha foi mantido constante com 5 plantas por metro linear em todos os tratamentos. Observou-se um efeito significativo do espaçamento na produção de matéria seca de ramos, folhas e raízes. As menores produções ocorreram nos maiores espaçamentos. A produção de sementes foi influenciada pelo espaçamento somente na primeira colheita. A altura das plantas não variou em função dos espaçamentos, porém aumentou em função da época de corte, devido ao maior tempo de desenvolvimento das plantas.

Palavras-chave: Biomassa; matéria seca; semente; tefrósia.
\end{abstract}

\section{Abstract}

Tephrosia candida plant spacing studies. The objective of this paper was to evaluate the seed and total biomass production of Tephrosia candida DC. in different row spacing and harvest period. The experiment was set under field conditions, the treatments were arranged in subplots in a randomized complete block design, and consisted of five row spacing $(20,40,60,80 \mathrm{e} 120 \mathrm{~cm})$ and three harvest period (12, 18 and 24 months from sowing). The row spacing was kept constant with five plants per linear meter in all treatments. A significant effect was observed from spacing in the dry matter production. Smalls productions had occurred in major spacing. Seed production was influenced by spacing only in the first harvest. The plant heights did not vary in function of spacing, but they increased as a function of the harvest period because the time of development of the plants.

Keywords: Biomass, dry matter, seed, white hoarypea.

\section{INTRODUÇÃO}

Tephrosia candida é um arbusto ereto de 1,2 a 2,5 m de altura, com grande adaptabilidade a solos ácidos e de baixa fertilidade, propagada por sementes, podendo tanto ser pastejada como também utilizada como adubo verde (WHYTE et al., 1968; PERIN et al., 1996; GOMES; MORAES, 1997). É uma espécie que apresenta a vantagem de poder fixar nitrogênio atmosférico por meio da associação com bactérias do gênero Rhizobium.

Oliveira et al. (2000) descrevem o fruto de T. candida como um legume de pericarpo pouco espesso e seco, com coloração variando de marrom-claro ao marrom-escuro, que apresenta em média nove sementes por fruto, com cotilédones elipsoidais de consistência carnosa e fendidos no ápice, com a radícula exposta, e que contém proteína, amido e tanino, sendo os dois primeiros os principais tipos de reservas da semente.

Amadalo et al. (2003) citam T. candida e outras espécies, como T. vogelii, Sesbania sesban e Cajanus cajan como adequadas para cultivo no Quênia, utilizando-as para a melhoria de solos, devido ao incremento da reciclagem de nutrientes (fósforo e nitrogênio, principalmente), e o controle de erosão. Também Mafongoya; Kuntashula (2005) ressaltam a importância da utilização de $T$. candida e $T$. vogelii como plantas recicladoras de nutrientes na Zâmbia, além da possibilidade de utilização de T. candida para produção de lenha. 
T. candida desperta o interesse pelo conteúdo de rotenóides em suas raízes. Os rotenóides têm atividade inseticida e foram usados no controle de pragas antes do advento dos inseticidas organossintéticos (JACOBSON; CROSBY, 1971). Além da atividade inseticida, os rotenóides apresentam atividade ictiotóxica poderosa, ou seja, são venenosos para peixes.

Assim, torna-se importante a avaliação da produção de sementes, por ser a principal forma de propagação da espécie, a quantificação da produção de raízes, por conterem princípios ativos utilizados como inseticidas, e da produção de folhas e ramos, utilizadas na adubação verde. O objetivo deste trabalho foi avaliar a produção de sementes, a altura de plantas e a produção de biomassa total (raízes, ramos e folhas) de $T$. candida em diferentes espaçamentos e épocas de corte.

\section{MATERIAL E MÉTODOS}

O experimento foi realizado na estação experimental do Instituto Agronômico do Paraná (IAPAR) em Londrina, Paraná. O clima que caracteriza a região é do tipo subtropical úmido, segundo a classificação climática de Koeppen, com temperatura média do mês mais quente superior a $22{ }^{\circ} \mathrm{C}$, do mês mais frio inferior a $18{ }^{\circ} \mathrm{C}$ e precipitação média anual de $1.614 \mathrm{~mm}$ (CORRÊA et al., 1982).

O solo foi preparado com grade pesada, seguido de aração e mais duas grades niveladoras. A semeadura no campo de $T$. candida foi realizada em 30/11/87, e a emergência das plantas ocorreu em 10/12/87. O desbaste foi realizado em 19/01/88, deixando-se cinco plantas por metro linear em todos os tratamentos.

As colheitas de sementes foram realizadas em 07/07/88 e em 09/05/89. As avaliações de altura de plantas, estande, produção de matéria seca das raízes e da parte aérea das plantas foram realizadas em 17/11/88 (12 meses), 17/05/89 (18 meses) e 31/01/90 (24 meses).

A altura da planta foi medida empregando-se uma régua a partir da base do solo, e a produção de matéria seca de ramos e folhas foi obtida através de cortes rentes ao solo, utilizando-se amostras de $1,00 \mathrm{~m} \mathrm{x}$ $1,00 \mathrm{~m}$, que posteriormente foram transformados em kg.ha ${ }^{-1}$. A coleta de raízes foi feita na entrelinha, respeitando os espaçamentos como comprimento, e utilizando-se uma vanga (ferramenta semelhante a uma pá superfície plana) de $100 \mathrm{~cm}$ de largura, para a retirada de porções de solo com raízes a uma profundidade de 0 a $30 \mathrm{~cm}$. Esses dados também foram transformados em kg.ha ${ }^{-1}$, respeitando os diferentes volumes de amostragem. A profundidade para a coleta de raízes foi efetuada somente na camada de maior concentração de raízes, profundidade essa viável para coleta visando extração de rotenóides.

O delineamento experimental utilizado foi de blocos ao acaso, com parcelas subdivididas, com cinco repetições. Nas parcelas, foram estudados 5 espaçamentos entre linhas: 20, 40, 60, 80 e $120 \mathrm{~cm}$; e nas subparcelas, 3 épocas de corte: 12,18 e 24 meses a partir da semeadura.

A área da parcela foi definida em $96 \mathrm{~m}^{2}(24 \times 4 \mathrm{~m})$, e da subparcela, $24 \mathrm{~m}^{2}(4,8 \times 5 \mathrm{~m})$, totalizando $2400 \mathrm{~m}^{2}$ como área total das parcelas e $2912 \mathrm{~m}^{2}$ como área total do ensaio. A quantidade de linhas totais e linhas úteis e as populações de plantas esperadas estão apresentadas na tabela 1.

Tabela 1. Número total de linhas, linhas úteis e população de plantas esperada para os diferentes espaçamentos de $T$. candida.

Table 1. Total of rows, useful rows and expected number of plants for hectare the different row spacing of $T$. candida.

\begin{tabular}{lccc}
\hline Espaçamento entre linhas (cm) & Número de linhas úteis & Número total de linhas & Plantas.ha $^{-1}$ \\
\hline 20 & 12 & 24 & 250000 \\
40 & 6 & 12 & 125000 \\
60 & 4 & 8 & 83500 \\
80 & 3 & 6 & 62500 \\
120 & 2 & 4 & 41500 \\
\hline
\end{tabular}

Os materiais coletados (folhas e ramos) foram colocados em estufa de circulação de ar forçado a $65{ }^{\circ} \mathrm{C}$ por $72 \mathrm{~h}$, para determinação da matéria seca. As raízes foram separadas do solo pela lavagem com jato d'água, em peneiras com malha de 2,0 mm, segundo Böhm (1976), e levadas para secagem em estufa com circulação forçada de ar, a $65^{\circ} \mathrm{C}$, por $72 \mathrm{~h}$, tempo suficiente para estabilizar o peso das amostras. 
Os dados foram submetidos à análise de variância e as médias foram comparadas entre si, pelo teste de Tukey a 5\% de probabilidade.

\section{RESULTADOS E DISCUSSÃO}

$\mathrm{Na}$ tabela 2 estão as produções médias de sementes nas duas épocas de colheita.

Tabela 2. Produção média de sementes de T. candida $\left(\mathrm{kg}_{\mathrm{g}} \mathrm{ha}^{-1}\right)$ em função dos espaçamentos entre linhas em duas épocas de colheita.

Table 2. T. candida seed production as a function of row spacing at two harvest period.

\begin{tabular}{lcc}
\hline Espaçamento entre linhas $\mathbf{( c m )}$ & $\mathbf{0 7 / 0 7 / 8 8}$ & $\mathbf{0 9 / 0 5 / 8 9}$ \\
\hline 20 & $157,17 \mathrm{cB} *$ & $935,83 \mathrm{aA}$ \\
40 & $416,50 \mathrm{bB}$ & $843,54 \mathrm{aA}$ \\
60 & $561,83 \mathrm{aB}$ & $771,86 \mathrm{aA}$ \\
80 & $500,67 \mathrm{abB}$ & $872,29 \mathrm{aA}$ \\
120 & $498,17 \mathrm{abB}$ & $855,83 \mathrm{aA}$ \\
* Médias seguidas de mesma letra minúscula na coluna e maiúscula na linha não diferem entre si pelo teste de Tukey, a 5\% de \\
significância.
\end{tabular}

Na primeira colheita (07/07/88), o espaçamento de $60 \mathrm{~cm}$ entre linhas propiciou maior produção de sementes, diferindo significativamente dos tratamentos 20 e $40 \mathrm{~cm}$, porém não diferindo estatisticamente dos espaçamentos 80 e $120 \mathrm{~cm}$. Os tratamentos 80 e $120 \mathrm{~cm}$ não diferiram do tratamento $40 \mathrm{~cm}$. O menor espaçamento $(20 \mathrm{~cm})$ apresentou a menor produção, diferindo estatisticamente dos demais tratamentos. A menor produção de sementes desse tratamento deveu-se, provavelmente, à forte competição entre plantas, com baixa taxa de pegamento de flores.

Na segunda colheita (09/05/89), não se verificou diferença estatística na produção de sementes entre os espaçamentos estudados. A ausência de resposta nesse segundo ano deve-se às diferentes conformações morfológicas das plantas, observadas nos diferentes espaçamentos. Nos menores espaçamentos, conseqüentemente, com maiores populações, havia menos hastes por planta e menores inflorescências, havendo, portanto, uma compensação entre os componentes de rendimento.

Comparando as colheitas de sementes realizadas, observa-se uma produção significativamente superior no segundo ano (Tabela 2), devido ao estádio de desenvolvimento das plantas. Nesse segundo ciclo de crescimento (Tabela 6), as plantas estabelecidas no ciclo anterior têm maior possibilidade de alocação de carbono em estruturas reprodutivas.

$\mathrm{Na}$ tabela 3 são apresentadas as alturas médias das plantas em função dos espaçamentos entre linhas nas diferentes épocas de corte.

Tabela 3. Altura média das plantas de T. candida $(\mathrm{m})$ em função dos espaçamentos entre linhas e diferentes épocas de corte.

Table 3. T. candida plant heights $(\mathrm{m})$ as a function of row spacing at two harvest period

\begin{tabular}{lccc}
\hline Espaçamento entre linhas $\mathbf{( c m )}$ & $\mathbf{1 2}$ meses & $\mathbf{1 8}$ meses & $\mathbf{2 4}$ meses \\
\hline 20 & 0,84 & 1,78 & 1,93 \\
40 & 0,83 & 1,73 & 1,96 \\
60 & 0,85 & 1,76 & 1,95 \\
80 & 0,81 & 1,73 & 2,00 \\
120 & 0,87 & 1,75 & 1,91 \\
\hline
\end{tabular}

A altura das plantas não sofreu variação na faixa de espaçamentos estudados, porém, registrou-se um aumento da altura das plantas em função da época de corte. Atrasando a época de corte, as plantas têm mais tempo para se desenvolver, o que pode ser benéfico para a proteção do solo contra erosão.

$\mathrm{Na}$ tabela 4, são apresentadas as populações de plantas em função do espaçamento nas diferentes épocas de corte. 
Tabela 4. População média de $T$. candida $\left(1000\right.$ plantas.ha $\left.^{-1}\right)$ e porcentagem de mortalidade total de plantas em função dos espaçamentos nas diferentes épocas de corte.

Table 4. T. candida population (1000 plants.ha $\left.{ }^{-1}\right)$ and total percentage of plant mortality as a function of row spacing at two harvest period.

\begin{tabular}{lccccc}
\hline Espaçamento entre linhas (cm) & Prevista & 12 meses & 18 meses & 24 meses & $\begin{array}{c}\text { Mortalidade } \\
\text { total (\%) }\end{array}$ \\
\hline 20 & 250,0 & 249,0 & 230,6 & 185,6 & 25,44 \\
40 & 125,0 & 125,0 & 122,9 & 109,0 & 42,83 \\
60 & 83,5 & 82,1 & 80,6 & 78,5 & 4,32 \\
80 & 62,5 & 62,5 & 62,5 & 61,0 & 2,33 \\
120 & 41,5 & 41,7 & 41,7 & 40,8 & 2,00 \\
\hline
\end{tabular}

Mantendo-se o mesmo número de plantas por metro linear, há uma redução na população de plantas com o aumento do espaçamento entre linhas (Tabela 4). Neste experimento, o número de plantas diminuiu em função das épocas de corte das plantas, o que pode ser explicado pela morte de algumas plantas no decorrer do experimento. Uma maior mortalidade nas maiores populações é esperada devido à maior competição pelos recursos disponíveis entre as plantas. A competição por água, luz e nutrientes pode ser elevada em altas populações.

$\mathrm{Na}$ tabela 5 estão os valores referentes às quantidades de raízes em função do espaçamento entre linhas nas diferentes épocas de corte.

Tabela 5. Quantidade de raízes de $T$. candida $\left(\mathrm{kg} \cdot \mathrm{ha}^{-1}\right.$ de matéria seca) em função dos espaçamentos entre linhas nas diferentes épocas de corte.

Table 5. T. candida root quantity (kg.ha ${ }^{-1}$ of dry matter) as a function of row spacing at two harvest period.

\begin{tabular}{lccc}
\hline Espaçamento entre linhas $\mathbf{( c m )}$ & $\mathbf{1 2}$ meses & $\mathbf{1 8}$ meses & 24 meses \\
\hline 20 & $3648,03 \mathrm{aB} *$ & $3707,44 \mathrm{aB}$ & $4663,75 \mathrm{aA}$ \\
40 & $2514,80 \mathrm{bB}$ & $2741,46 \mathrm{bB}$ & $3963,75 \mathrm{bA}$ \\
60 & $1579,68 \mathrm{cC}$ & $2312,61 \mathrm{cB}$ & $3036,25 \mathrm{cA}$ \\
80 & $1404,66 \mathrm{cdC}$ & $1999,48 \mathrm{cdB}$ & $2760,63 \mathrm{cdA}$ \\
120 & $1210,19 \mathrm{dC}$ & $1701,04 \mathrm{~dB}$ & $2458,75 \mathrm{dA}$ \\
\hline
\end{tabular}

* Médias seguidas de mesma letra minúscula na coluna e maiúscula na linha não diferem entre si pelo teste de Tukey a 5\% de significância.

A quantidade de raízes diminuiu conforme aumentou o espaçamento entre linhas (Tabela 5), o que pode ser atribuído ao maior número de plantas nos menores espaçamentos. Nas três épocas de avaliação, a quantidade total de raízes diminuiu com o aumento do espaçamento e com a conseqüente redução da população de plantas. Na última época de corte (24 meses), constatou-se maior quantidade de raízes que, quando comparadas com as demais, diferiu estatisticamente em todos os espaçamentos testados. Na segunda época (18 meses), a quantidade de raízes foi superior à obtida na primeira época (12 meses) nos espaçamentos 60,80 e $120 \mathrm{~cm}$, não diferindo nos menores espaçamentos estudados.

Os rotenóides presentes em $T$. candida são extraídos das raízes, assim, os menores espaçamentos apresentaram maior quantidade de raízes e também maior produção de rotenóides em função do atraso na época de colheita. Porém, observa-se que a quantidade de raízes obtidas aos 12 meses, quando comparada aos 24 meses, nos menores espaçamentos $(20$ e $40 \mathrm{~cm}$ ), pode ser mais vantajosa, pois em dois ciclos a produção acumulada poderia ser maior que a obtida com o atraso na época de colheita.

Na tabela 6 estão os resultados de produção de matéria seca de ramos e folhas de T. candida $\left(\mathrm{kg} \cdot \mathrm{ha}^{-1}\right)$ em função do espaçamento entre linhas nas diferentes épocas de corte.

A produção de matéria seca de ramos e folhas diminuiu conforme aumentou o espaçamento entre linhas (Tabela 6), similar ao ocorrido com a quantidade de raízes (Tabela 5), pela diminuição na população de plantas. Nas três épocas de corte, a produção de matéria seca foi maior no menor espaçamento, possivelmente pela maior população de plantas (Tabela 4), diminuindo com o aumento do espaçamento. A última época de corte (24 meses) proporcionou maior produção de matéria seca de ramos 
e folhas, diferindo estatisticamente das demais épocas em todos os espaçamentos testados. Já a produção na segunda época de corte (18 meses) foi superior à produção na primeira época (12 meses), diferindo estatisticamente em todos os espaçamentos estudados. $\mathrm{O}$ aumento da produção de matéria seca em função do maior tempo de desenvolvimento das plantas pode ser importante para a decisão do manejo das plantas, pois, com um maior tempo de crescimento, as plantas tendem a acumular mais nutrientes na biomassa, tendo importância na reciclagem de nutrientes e melhoria das condições do solo.

Tabela 6. Produção de matéria seca total de ramos e folhas de $T$. candida (kg.ha ${ }^{-1}$ ) em função do espaçamento entre linhas nas épocas de corte.

Table 6. T. candida total production of branches and leaves dry matter $\left(\mathrm{kg} \cdot \mathrm{ha}^{-1}\right)$ as a function of row spacing at two harvest period.

\begin{tabular}{lccc}
\hline Espaçamento entre linhas (cm) & $\mathbf{1 2}$ meses & $\mathbf{1 8}$ meses & $\mathbf{2 4}$ meses \\
\hline 20 & $5087,83 \mathrm{aC} *$ & $7545,40 \mathrm{aB}$ & $10215,33 \mathrm{aA}$ \\
40 & $3356,38 \mathrm{bC}$ & $5789,23 \mathrm{bB}$ & $9363,33 \mathrm{bA}$ \\
60 & $2796,73 \mathrm{bcC}$ & $5521,10 \mathrm{bcB}$ & $7623,33 \mathrm{cA}$ \\
80 & $2481,27 \mathrm{cC}$ & $4824,84 \mathrm{cB}$ & $7153,33 \mathrm{cA}$ \\
120 & $2345,63 \mathrm{cC}$ & $3975,25 \mathrm{~dB}$ & $6920,00 \mathrm{cA}$ \\
\hline * Médias seguidas de mesma letra minúscula na coluna e maiúscula na linha não diferem entre si pelo teste de Tukey a \\
\multicolumn{2}{l}{ 5\% de significância. }
\end{tabular}

Gomes; Moraes (1997) recomendam para o estado do Acre espaçamento de 1,0 m entre linhas por $0,30 \mathrm{~m}$ entre plantas para a semeadura de $T$. candida como adubo verde. Nesse espaçamento, estimaram a produção de $8000 \mathrm{~kg} \cdot \mathrm{ha}^{-1}$ de matéria seca e uma produção de $400 \mathrm{~kg}$ de sementes por hectare, produções obtidas neste trabalho aos 24 meses para matéria seca e aos 12 meses para sementes.

Garcia (2002), avaliando espécies de leguminosas para adubação verde em solos arenosos de Tabuleiros Costeiros no Piaú, efetuou a semeadura de $T$. candida no espaçamento de $40 \mathrm{~cm}$ entre linhas e 20 plantas por metro linear em sistema irrigado e obteve uma produção de $5255 \mathrm{~kg}$.ha ${ }^{-1}$ de matéria seca aos 100 dias após a semeadura e produção de $1593 \mathrm{~kg} \cdot \mathrm{ha}^{-1}$ de sementes aos seis meses após a semeadura, produções superiores às obtidas neste trabalho.

\section{CONCLUSÕES}

Espaçamentos reduzidos propiciam maior produção de matéria seca, porém com menores produções de sementes no primeiro ciclo de crescimento. O atraso na época de corte propicia maior acúmulo de biomassa. Menores espaçamentos podem proporcionar uma produção de raízes antecipada e ser vantajosa para extração de rotenóides. Para colheita de sementes, um segundo ciclo de crescimento proporciona uma maior produção. Os espaçamentos não influenciaram na altura das plantas, porém em cortes mais tardios as alturas foram maiores.

\section{REFERÊNCIAS}

AMADALO, B.; JAMA, B.; NIANG, A.; NOORDIN, Q.; NYASIMI, M.; PLACE, F.; FRANZEL, S.; BENIEST, J. Improved fallows for western Kenya: an extension guideline. Nairobi: World Agroforestry Centre, 2003, p.56.

BÖHM, W. In situ estimation of root length at natural soil profiles. Journal Of Agricultural Science, Cambridge, v.87, p.365-368, 1976.

CORRÊA, A. R.; GODOY, H.; BERNARDES, R. L. M. Características climáticas de Londrina. 2.ed. Londrina: IAPAR, 1982. 16p. (Circular, 5).

GARCIA, L. F. Introdução e avaliação de leguminosas para adubação verde em solos arenosos de tabuleiros costeiros do Piauí. Revista de la Facultad de Agronomía, Maracay, v.28, n.1, p. 93-103. 2002 . 
GOMES, T. C. A.; MORAES, R. N. S. Recomendação para o plantio de espécies leguminosas para o manejo de solos no acre. Rio Branco, AC: Embrapa Centro de Pesquisa Agroflorestal do Acre, 1997, p. 1-3. (Comunicado técnico, n.77)

JACOBSON, M.; CROSBY, D. G. Naturally Occurring Insecticides. NewYork: Marcel Dekker, 1971. p.71-73.

MAFONGOYA, P. L.; KUNTASHULA, E. Participatory evaluation of Tephrosia species and provenances for soil fertility improvement and other using farmer criteria in Eastern Zambia. Ex Experimental agriculture, London, v.41, p.69-80, 2005.

OLIVEIRA, A. N.; QUEIROZ, M. S. M.; RAMOS, M. B. P. Estudo morfológico de frutos e sementes de tefrósia (Tephrosia candida DC. - Papilionoideae) na Amazônia Central. Revista Brasileira de Sementes, Brasília, DF, v.22, n.2, p.193-199, 2000.

PERIN, R.; CORRÊA, J. C.; CRAVO, M. S.; CANTO, A. C.; MATOS, J. C. S. Desempenho produtivo de leguminosas arbustivas de múltiplo uso com baixos níveis de fósforo. In: REUNIÃO BRASILEIRA DE FERTILIDADE DO SOLO E NUTRIÇÃO DE PLANTAS, 22, Manaus, 1996. Anais... Manaus: Sociedade Brasileira de Ciência do Solo, 1996. v.1, p.456-457.

WHYTE, R. O.; NILSSON-LEISSNER, G.; TRUMBLE, H. C. Las leguminosas en la agricultura. Yugoslavia: FAO - Organización de las naciones unidas para la agricultura y la alimentación, 1968. p.405. 